SECTION 31. Economic research, finance, innovation, risk management.

Anna Sergeevna Kravchenko

$\mathrm{PhD}$ student of Department «Economic analysis» Kuban State Agrarian University, Krasnodar, Russia

anna.kravchenko.92@inbox.ru

Vasily Evgenyevich Polyakov

Assistant of Department «Economic analysis»

Kuban State Agrarian University, Krasnodar, Russia

polyakov.ve@gmail.com

\title{
ANALYSIS AND ASSESSMENT OF THE INFLUENCE OF CAPITAL STRUCTURE ON THE FINANCIAL SITUATION OF THE AGRICULTURAL ORGANIZATIONS OF THE KRASNODAR REGION
}

\begin{abstract}
Defined the dynamics of capital structure of medium and large agricultural organizations of the Krasnodar region for 10 years. Evaluated its impact on efficiency of their operations and financial condition. Set the optimal ratio between own and borrowed funds.

Key words: Analysis, capital, financial stability, financial condition, efficiency of operations.

Citation: Kravchenko AS, Polyakov VE (2014) ANALYSIS AND ASSESSMENT OF THE INFLUENCE OF CAPITAL STRUCTURE ON THE FINANCIAL SITUATION OF THE AGRICULTURAL ORGANIZATIONS OF THE KRASNODAR REGION. ISJ Theoretical \& Applied Science 8 (16): 89-93.
\end{abstract}

\section{АНАЛИЗ И ОЦЕНКА ВЛИЯНИЯ СТРУКТУРЫ КАПИТАЛА НА ФИНАНСОВОЕ ПОЛОЖЕНИЕ СЕЛЬСКОХОЗЯЙСТВЕННЫХ ОРГАНИЗАЦИЙ КРАСНОДАРСКОГО КРАЯ}

Аннотация: Определена динамика структуры капитала средних и крупных сельскохозяйственных организаций Краснодарского края за 10 лет. Оченено ее влияние на эффективность их деятельности и финансовое состояние. Установлено оптимальное соотношение между собственными и заемными средствами.

Ключевые слова: Анализ, капитал, финансовая устойчивость, финансовое состояние, эффективность деятельности.

При анализе устойчивости финансового положения особое внимание уделяют сложившемуся соотношению между собственными и заемными источниками финансирования деятельности хозяйствующего субъекта. В мировой учетно-аналитической практике сложилась точка зрения, что оптимальное соотношение между собственным и заемным капиталом составляет $50 \%$ на $50 \%$ или $60 \%$ на $40 \%$. В первом случае исходят из критерия максимизации уровня финансовой рентабельности на основе использования механизма финансового левериджа. Во втором - из критерия минимизации стоимости капитала на основе оценки стоимости собственного и заемного капитала при различных условиях его привлечения и последующем расчете средневзвешенной стоимости всего капитала на основе многовариантных расчетов [3, с. 449 - 454]. Оба этих подхода, а соответственно и рассчитанные на их основе значения, апробированы в западных экономических условиях и не в полной мере учитывают особенности отечественного законодательства и условия хозяйствования. В связи с этим экономисту при оценке финансовой устойчивости предприятия следует ориентироваться не столько на эти «оптимальные» значения, сколько на свой опыт и особенности функционирования 
исследуемой организации.

В условиях неочевидности выбора оптимальной структуры капитала определенный интерес представляет сложившееся за некоторый промежуток времени соотношение между собственными и заемными средствами реально функционирующих субъектов хозяйствования конкретной отрасли экономики.

Мы проанализировали за 2003 - 2012 гг. средний уровень финансового положения средних и крупных сельскохозяйственных организаций Краснодарского края и определили соотношение между собственными и заемными средствами (рис. 1).

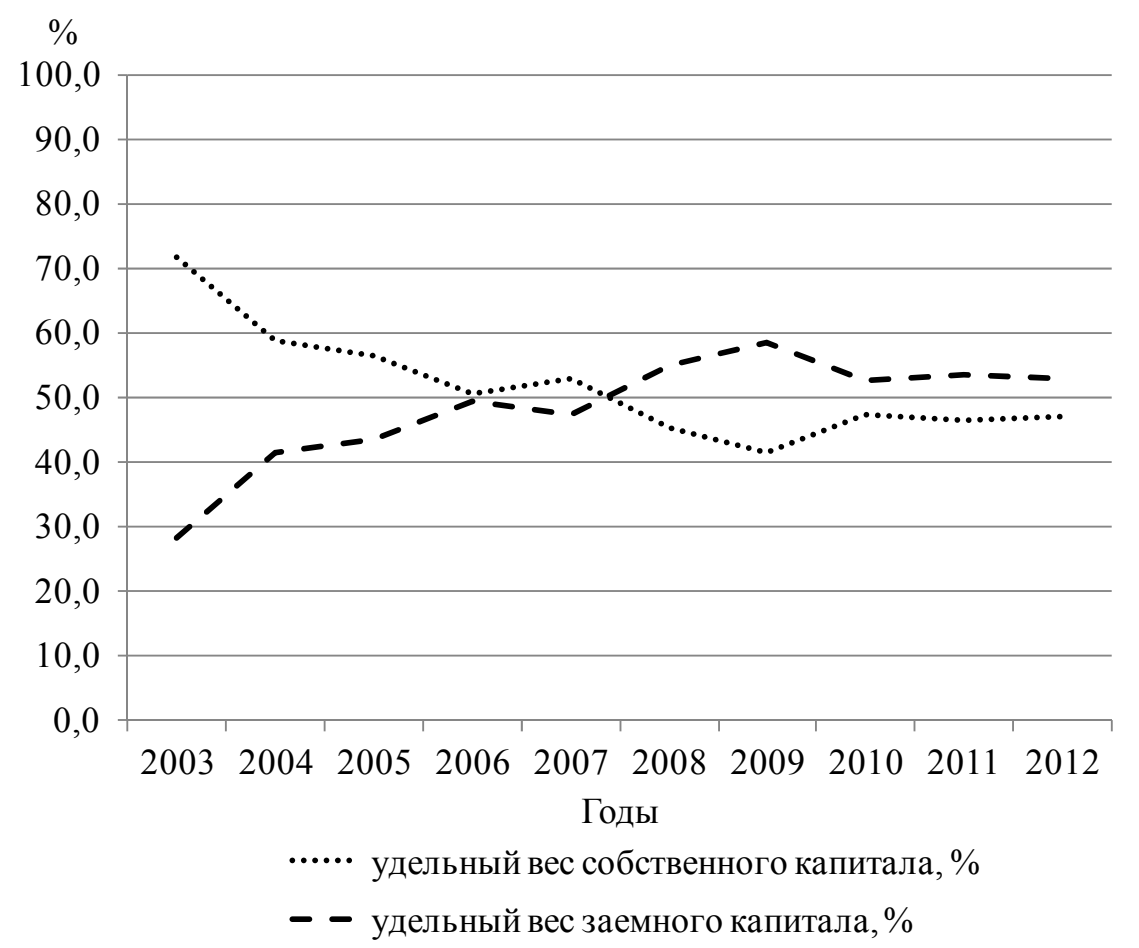

Рисунок 1 - Динамика структуры капитала средних и крупных сельскохозяйственных организации Краснодарского края за 2003 - 2012 гг.

Как следует из рисунка до 2006 г. рост имущества сельскохозяйственных организаций края был обеспечен в большей степени за счет собственных источников, в 2006 - 2007 гг. соотношение собственных и заемных средств было практически одинаковым, с 2008 г. по 2010 г. наблюдается преобладание заемных средств, и в последние два года среднеотраслевой показатель стремится к оптимальному с точки зрения максимизации финансовой рентабельности соотношению собственного и заемного капитала - 50 \% на $50 \%$.

Чтобы оценить оптимальность сложившейся в средних и крупных сельскохозяйственных организациях Краснодарского края структуры капитала необходимо определить влияние соотношения собственных и заемных средств на уровень финансового положения исследуемых хозяйствующих субъектов.

Для этого нами была проведена группировка основных показателей эффективности деятельности 185 средних и крупных сельскохозяйственных организаций Краснодарского края в зависимости от величины коэффициента автономии, который показывает долю собственных средств в общей величине источников финансирования и может служить критерием, характеризующим структуру капитала организаций (таблица 1).

Как следует из таблицы наибольшие значения выручки и прибыли наблюдаются по группе предприятий с долей собственных средств от 46 \% до 64 \%. Эффективность использования имущества по этой группе также наиболее высока: с каждого рубля, 
вложенного в активы эти предприятия получали 70 коп. выручки и 11 коп. чистой прибыли.

Таблица 1

Основные финансовые показатели деятельности средних и крупных сельскохозяйственных организаций Краснодарского края в среднем за 2010 - 2012 гг., сгруппированные по величине коэффициента автономии

\begin{tabular}{|l|c|c|c|c|c|c|}
\hline \multirow{2}{*}{ Показатель } & \multicolumn{5}{|c|}{ Величина показателя в среднем по группе хозяйств } \\
\cline { 2 - 7 } & $\begin{array}{c}\text { до } \\
\mathbf{0 , 2 7 9}\end{array}$ & $\begin{array}{c}\mathbf{0 , 2 8 0}-\mathbf{0 , 4 6 1} \\
\mathbf{0}\end{array}$ & $\begin{array}{c}\mathbf{0 , 4 6 2}-\mathbf{0 , 6 4 3} \\
\mathbf{0}\end{array}$ & $\begin{array}{c}\mathbf{0 , 6 4 4} \text { - } \\
\mathbf{0 , 8 2 5}\end{array}$ & $\begin{array}{c}\text { свыше } \\
\mathbf{0 , 8 2 5}\end{array}$ & $\begin{array}{c}\text { итого и в } \\
\text { среднем }\end{array}$ \\
\hline Количество хозяйств в группе & 237312 & 310196 & 322832 & 306088 & 257603 & 289148 \\
\hline Выручка, тыс. руб. & 38714 & 57517 & 73131 & 54624 & 57136 & 57843 \\
\hline Прибыль от продаж, тыс. руб. & & & & & & \\
\hline $\begin{array}{l}\text { Прибыль до налогообложения, } \\
\text { тыс. руб. }\end{array}$ & 21910 & 35495 & 58105 & 48623 & 49610 & 45595 \\
\hline Чистая прибыль, тыс. руб. & 21183 & 34740 & 56299 & 46645 & 47939 & 44092 \\
\hline $\begin{array}{l}\text { Коэффициент оборачиваемости } \\
\text { имущества }\end{array}$ & 0,538 & 0,576 & 0,704 & 0,696 & 0,672 & 0,653 \\
\hline $\begin{array}{l}\text { Коэффициент оборачиваемос-ти } \\
\text { оборотных активов }\end{array}$ & 1,198 & 1,214 & 1,449 & 1,445 & 1,310 & 1,340 \\
\hline $\begin{array}{l}\text { Коэффициент оборачиваемос-ти } \\
\text { собственного капитала }\end{array}$ & 2,567 & 1,628 & 1,194 & 0,972 & 0,734 & 1,231 \\
\hline Фондоотдача, руб. & 2,15 & 1,50 & 2,01 & 1,83 & 1,70 & 1,80 \\
\hline Рентабельность продаж, \% & 16,16 & 17,55 & 21,47 & 18,47 & 22,25 & 19,73 \\
\hline $\begin{array}{l}\text { Рентабельность реализованной } \\
\text { продукции, \% }\end{array}$ & 21,29 & 23,34 & 30,95 & 24,51 & 30,75 & 27,01 \\
\hline Рентабельность имущества, \% & 4,73 & 5,98 & 10,95 & 10,42 & 11,63 & 9,47 \\
\hline $\begin{array}{l}\text { Рентабельность собственного } \\
\text { капитала, \% }\end{array}$ & 21,81 & 16,43 & 18,89 & 14,32 & 12,55 & 15,86 \\
\hline $\begin{array}{l}\text { Рентабельность внеоборотных } \\
\text { активов, \% }\end{array}$ & 11,42 & 14,32 & 26,64 & 23,12 & 27,37 & 22,20 \\
\hline $\begin{array}{l}\text { Рентабельность оборотных } \\
\text { активов, \% }\end{array}$ & 12,39 & 12,76 & 23,72 & 21,72 & 22,71 & 19,79 \\
\hline
\end{tabular}

Это связано с эффективным использованием как оборотных активов (коэффициент их оборачиваемости и рентабельность - наивысшие среди исследуемой совокупности 1,449 оборота в год и 23,72\%), так и внеоборотных, а в частности основных средств. С каждого рубля, вложенного в основные фонды, предприятия этой группы получали 2 руб. выручки. Большее значение наблюдается только по первой группе предприятий со значением коэффициента автономии менее 0,279 пункта.

Эффективность коммерческой деятельности предприятий третьей группы, характеризуемая показателями рентабельности продаж и реализованной продукции, существенно выше, чем у остальных организаций. Сходные значения наблюдаются только в пятой группе при наибольшей величине собственных средств.

Между рентабельностью собственного капитала и коэффициентом автономии наблюдается обратная зависимость. Это объясняется действием финансового рычага, который, как известно, приводит к росту рентабельности собственного капитала при привлечении заемных средств [4, с. 211; 8, с. 150].

В целом на основе проведенного анализа можно сделать вывод, что предприятия с долей собственного капитала от $46 \%$ до 64 \% характеризуются наиболее высокой 
эффективностью деятельности.

Кроме оценки эффективности деятельности необходимо исследовать влияние структуры капитала ни финансовое положение организаций края. Для этого нами была проведена группировка основных показателей финансового состояния отобранных предприятий в зависимости от величины коэффициента автономии (таблица 2).

Таблица 2

Основные показатели финансового состояния средних и крупных сельскохозяйственных организаций Краснодарского края в среднем за 2010 - 2012 гг., сгруппированные по величине коэффициента автономии

\begin{tabular}{|c|c|c|c|c|c|c|}
\hline \multirow[b]{2}{*}{ Показатель } & \multicolumn{6}{|c|}{ Величина показателя в среднем по группе хозяйств } \\
\hline & $\begin{array}{c}\text { до } \\
\mathbf{0 , 2 7 9}\end{array}$ & $\begin{array}{c}0,280- \\
0,461\end{array}$ & $\begin{array}{c}0,462- \\
0,643\end{array}$ & $\begin{array}{c}0,644- \\
0,825\end{array}$ & $\begin{array}{c}\text { свыше } \\
\mathbf{0 , 8 2 5}\end{array}$ & $\begin{array}{c}\text { итого и в } \\
\text { среднем }\end{array}$ \\
\hline Количество хозяйств в группе & 19 & 34 & 36 & 43 & 53 & 185 \\
\hline $\begin{array}{l}\text { Коэффициент финансовой } \\
\text { независимости }\end{array}$ & 0,644 & 0,633 & 0,732 & 0,803 & 0,945 & 0,771 \\
\hline Коэффициент финансирования & 0,277 & 0,556 & 1,355 & 2,628 & 13,016 & 1,585 \\
\hline $\begin{array}{l}\text { Коэффициент маневренности } \\
\text { собственного капитала }\end{array}$ & $-1,553$ & $-0,382$ & 0,151 & 0,289 & 0,468 & 0,179 \\
\hline $\begin{array}{l}\text { Коэффициент обеспеченности } \\
\text { собственными оборотными } \\
\text { средствами }\end{array}$ & $-0,753$ & $-0,270$ & 0,170 & 0,432 & 0,859 & 0,221 \\
\hline $\begin{array}{l}\text { Коэффициент обеспеченности } \\
\text { запасов и затрат собственны-ми } \\
\text { оборотными средствами }\end{array}$ & $-1,545$ & $-0,571$ & 0,333 & 0,701 & 1,217 & 0,386 \\
\hline $\begin{array}{l}\text { Коэффициент абсолютной } \\
\text { ликвидности }\end{array}$ & 0,326 & 0,207 & 0,308 & 0,327 & 1,614 & 0,359 \\
\hline $\begin{array}{l}\text { Коэффициент быстрой } \\
\text { ликвидности }\end{array}$ & 0,624 & 0,705 & 0,877 & 0,937 & 2,665 & 0,897 \\
\hline $\begin{array}{l}\text { Коэффициент текущей } \\
\text { ликвидности }\end{array}$ & 1,256 & 1,377 & 1,911 & 2,461 & 9,182 & 2,166 \\
\hline
\end{tabular}

Значения всех коэффициентов увеличиваются по мере роста доли собственных средств в структуре баланса. Это свидетельствует об улучшении финансового положения исследуемых предприятий. Основываясь на рекомендуемых в учебной литературе [2, с. 81; 7, с. 487] и нормативно-правовых актах значениях рассчитанных показателей, следует признать финансовое положение предприятий с долей собственных средств менее $46 \%$ неудовлетворительным. Эти хозяйства существенно зависят от внешних источников финансирования, у них отсутствуют собственные оборотные средства, т.е. все оборотные и часть внеоборотных активов сформированы за счет заемных источников. Платежеспособность этих предприятий также недостаточна. Значения коэффициентов абсолютной и быстрой ликвидности находятся в рекомендуемых пределах $[1$, с. $77 ; 9$, с. 346], однако степень покрытия текущих обязательств оборотными активами свидетельствует о том, что в случае необходимости досрочно погасить краткосрочные обязательства эти предприятия окажутся в очень сложном финансовом положении и, возможно, не смогут продолжать свою деятельность, т.к. вынуждены будут продать большую часть имущества.

Начиная с третьей группы (предприятия с долей собственного капитала от 46 \% до 
$64 \%)$ финансовое положение организаций меняется от нормального до абсолютно устойчивого. Таким образом, наблюдается прямая зависимость между структурой капитала и финансовым положением предприятия.

Возвращаясь к результатам оценки эффективности деятельности следует отметить, что при наращивании собственного капитала свыше $64 \%$ несмотря на улучшение финансового положения наблюдается снижение показателей деловой активности организаций. Это происходит вследствие накопления излишней величины оборотных средств и обездвиживания денежных средств на счетах в банках.

Таким образом, следует признать чрезмерное наращивание собственного капитала нецелесообразным. Оптимальное для исследуемой совокупности организаций значение удельного веса собственных средств находится в интервале от $46 \%$ до 64 \%. В $2010-2012$ гг. среднеотраслевой показатель по Краснодарскому краю находится в нижней границе указанного диапазона и соответствует $47 \%$, что свидетельствует о недостаточно устойчивом состоянии отрасли.

В заключение мы провели анализ структуры капитала у сельскохозяйственных организаций края различных организационно-правовых форм. К наиболее финансово устойчивыми следует отнести сельскохозяйственные производственные кооперативы (СПК) (у четверти из них доля собственных средств составляла от $60 \%$ до $80 \%$, а у остальных - свыше 80 \%). На втором месте идут федеральные государственные унитарные предприятия (ФГУПы). Примерно две трети из них (64,3 \%) имеют значение коэффициента автономии более 0,8 пункта, $21 \%$ - от 0,6 до 0,8 пункта, и только $14 \%$ - менее 0,4 пункта. Более половины исследуемых акционерных обществ имеют долю собственного капитала свыше $60 \%$. Наихудшие значения наблюдаются по обществам с ограниченной ответственностью (ООО). Только 40 \% данных предприятий имеют значение коэффициент автономии более 0,6 пункта. Вместе с тем это самая распространенная организационноправовая форма среди исследуемой совокупности предприятий.

\section{References:}

1. MA Vahrushinoy, NS Plaskovoy (2007) Analiz finansovoy otchetnosti: uchebnik. Moscow, Vuzovskiy uchebnik, pp. 367.

2. Bank VR, Bank SV, Taraskina AV (2006) Finansovyy analiz: ucheb. posobie. Moscow, TK Velbi, Izd-vo Prospekt, pp. 344.

3. Blank IA (2007) Osnovy finansovogo menedzhmenta. Tom 1, 3-e izd., ster., Kiev, NikaCentr, pp.592.

4. Kovalev VV (2008) Kurs finansovogo menedzhmenta: ucheb. Moscow, TK Velbi, Izd-vo Prospekt, pp. 448.

5. Kogdenko VG (2011) IEkonomicheskiy analiz: ucheb. posobie. 2-e izd., pererab. i dop., Moscow, YUNITI, pp. 399.

6. Lyubushin NP (2010) IEkonomicheskiy analiz: uchebnik 3-e izd., pererab. i dop., Moscow, YUNITI-DANA, pp. 575.

7. Savickaya GV (2009) Analiz hozyaystvennoy deyatel'nosti predpriyatiya: uchebnik. 5-e izd., pererab. i dop., Moscow, INFRA-M, pp. 536.

8. ES Stoyanovoy (2010) Finansovyy menedzhment: teoriya i praktika: uchebnik. 6-e izd., Moscow, Izd-vo «Perspektiva», pp. 656.

9. Sheremet AD (2006) Kompleksnyy analiz hozyaystvennoy deyatel'nosti. Moscow, INFRAM, pp. 415.

10. LT Gilyarovskoy (2004) IEkonomicheskiy analiz: uchebnik dlya vuzov. 2-e izd., dop., Moscow, YUNITI - DANA, pp. 615. 